\title{
Small molecule-induced simultaneous destabilization of $\beta$-catenin and RAS is an effective molecular strategy to suppress stemness of colorectal cancer cells
}

Yong-Hee Cho ${ }^{1,2}$, Eun Ji Ro ${ }^{1,2}$, Jeong-Su Yoon ${ }^{1,2}$, Dong-Kyu Kwak ${ }^{1,2}$, Jaebeom Cho ${ }^{3}$, Dong Woo Kang ${ }^{4}$, Ho-Young Lee ${ }^{3}$ and Kang-Yell Choi ${ }^{1,2,5^{*}}$

\begin{abstract}
Background: Cancer stem cells (CSCs), the major driver of tumorigenesis, is a sub-population of tumor cells responsible for poor clinical outcomes. However, molecular mechanism to identify targets for controlling CSCs is poorly understood.

Methods: Gene Set Enrichment Analyses (GSEA) of Wnt/ $\beta$-catenin and RAS signaling pathways in stem-like subtype of colorectal cancer (CRC) patients were performed using two gene expression data set. The therapeutic effects of destabilization of $\beta$-catenin and RAS were tested by treatment of small molecule KYA1797K using CRC patient derived cells.

Results: Treatment with KYA1797K, a small molecule that destabilizes both $\beta$-catenin and RAS via Axin binding, effectively suppresses the stemness of CSCs as shown in CRC spheroids and small intestinal tumors of $A^{A p C^{M i n} /+} / K-R_{a s}{ }^{G 12 D} L A 2$ mice. Moreover, KYA1797K also suppresses the stemness of cells in CRC patient avatar model systems, such as patient-derived tumor organoids (PDTOs) and patient-derived tumor xenograft (PDTX).
\end{abstract}

Conclusion: Our results suggest that destabilization of both $\beta$-catenin and RAS is a potential therapeutic strategy for controlling stemness of CRC cells.

Keywords: Cancer stem cells, $\beta$-Catenin, RAS, Destabilization, KYA1797K

\section{Background}

Colorectal cancer (CRC) is the third most commonly diagnosed cancer worldwide [1], and has remained a major cause of cancer-associated mortality mainly due to the metastasis and recurrence [2]. Cancer stem cells (CSCs), the sub-population of tumor cells that possess stem cell properties, plays critical roles in the initiation and progression of $\mathrm{CRC}$, and are considered as main culprits that contribute to

\footnotetext{
* Correspondence: kychoi@yonsei.ac.kr

'Translational Research Center for Protein Function Control, Yonsei University, Seoul, South Korea

2Department of Biotechnology, College of Life Science and Biotechnology, Yonsei University, Seoul, South Korea

Full list of author information is available at the end of the article
}

the metastasis and recurrence of CRC [3-6]. A recent clinical study revealed that CRC patients who possess the tumors with high stem cell properties have critically short disease free survival (DFS) rates compared with those who possess differentiated tumors [7]. However, drugs to control CSCs as well as the molecular targets for development of such drugs have not yet been identified.

The Wnt/ $\mathrm{W}$-catenin pathway is a major signaling pathway that maintains intestinal homeostasis via regulation of intestinal stem cells (ISCs) and their precursor cells [8]. Mutation of Adenomatous polyposis coli $(A P C)$ which occurs in more than $90 \%$ of CRC patients, is an initial event for induction of CSCs and tumor formation. Indeed, convincing 
molecular markers representing CSCs in CRC including leucine-rich repeat-containing G-protein coupled receptor 5 (LGR5), CD44, and CD133 are the transcriptional targets of Wnt/ $\beta$-catenin pathway [9-11]. Recent studies using lineage tracing in animal models revealed that stem-cellspecific loss of $A p c$ resulted in progressive growth of neoplasia by transformation of their progenitor cells [3].

KRAS mutations, which occur in 50\% of advanced CRC patients, activate both extracellular signal-regulated kinase (ERK) and phosphatidyl inositol 3-kinase (PI3K)AKT signaling pathways, and subsequently induce proliferation of ISCs [12, 13]. Although Kras mutation alone does not induce CSC activation or the tumor formation in murine small intestine, co-occurrence of mutations in both $A p c$ and Kras enriches and activates CSCs via synergistic activation of the Wnt/ $\beta$-catenin pathway [1416]. Therefore, inhibition of both pathways has been suggested as an effective strategy for suppression of CSCs as a treatment for CRC $[17,18]$.

In this study, we analyzed the genomic expression profiles of stem-like subtypes of CRC patient tissues possessing CSC characteristics using two gene expression data set (GSE13294; $N=125$, GSE14333; $N=246$ ) derived from resected primary CRC tissues [7]. Interestingly, we found that the expression levels of the Wnt/ $\beta$-catenin and RAS/ MAPK signaling pathways target genes are highly increased in stem-like subtype of CRC patient tissues compared with other differentiated subtypes of CRC patients. In addition, both $\beta$-catenin and RAS protein, as well as the GTP-bound active RAS levels were also highly elevated in the CSC-like populations possessing stem cell characteristics compared with non-CSC like populations of CRC cell lines classified by fluorescent activating cell sorting (FACS). KYA1797K, a small molecule that destabilize both $\beta$-catenin and RAS by activating GSK3 $\beta$ via binding with Axin [19], effectively suppressed the stemness of CRC spheroids with their growth inhibition.

Moreover, KYA1797K effectively suppressed the stemness of CSCs in small intestinal tumors of $\mathrm{Apc}^{\mathrm{Min} /+} /$ Kras ${ }^{G 12 D} L A 2$ mice as well as patient avatar models such as patient-derived tumor organoids (PDTOs) and patientderived tumor xenograft model (PDTX). In addition, KYA1797K effectively induced differentiation in metastatic CRC PDTX tissues as shown by increased expression of KRT20, a convincing differentiation marker of CRC. Taken together, we suggest that a small moleculeinduced destabilization of both $\beta$-catenin and RAS is the potential therapeutic approach to suppress the stemness of CSCs with clinical implications for treatment of CRC.

\section{Methods}

\section{Cell cultures and reagents}

Human CRC cells (HCT15, DLD1, SW48, SW480, SW620, Widr, RKO, and HCT116) were purchased from the
American Type Culture Collection (Manassas, VA, USA). DLD-1 harboring mutant KRAS [20]. was provided by B. Vogelstein (John Hopkins Oncology Center, Baltimore, MD, USA). All cell lines were authenticated using short tandem repeat profiling (Cosmogenetech, Korea) and were maintained in RPMI1640 (Gibco, Carlsbad, CA, USA) or DMEM (Gibco) supplemented with 10\% fetal bovine serum (Gibco). KYA1797K was dissolved in dimethyl sulfoxide (Sigma-Aldrich, St. Louis, MO, USA) for in vitro studies.

\section{Immunoblotting}

Cells were washed with ice-cold PBS and lysed using radio-immunoprecipitation assay (RIPA) buffer $(150 \mathrm{mM}$ $\mathrm{NaCl} ; 10 \mathrm{mM}$ Tris, $\mathrm{pH} 7.2 ; 0.1 \%$ sodium dodecyl sulfate; $1 \%$ Triton X-100; $1 \%$ sodium deoxycholate; and $5 \mathrm{mM}$ ethylenediaminetetraacetic acid). Samples of mouse tissues stored in liquid nitrogen were prepared in RIPA buffer and then homogenized. Proteins were separated on a 10 $12 \%$ sodium dodecyl sulfate polyacrylamide gel and transferred to a nitrocellulose membrane (Whatman, Little Chalfont, UK). Immunoblotting was performed with the following primary antibodies: anti-pan-RAS monoclonal (Millipore, MA, USA, MBS195; 1:3000), anti- $\beta$-catenin (Santa Cruz Biotechnology, TX, USA, sc-7199; 1:3000), anti-c-Myc (Santa Cruz Biotechnology, sc-789; 1:1000), anti-p-ERK (Cell Signaling Technology, sc514302; 1:1000), anti-p-AKT (Cell Signaling Technology, \#4060 s; 1:1000), and anti- $\beta$-actin (Santa Cruz Biotechnology, sc-47,778; 1: 5000). Horseradish peroxidase-conjugated anti-mouse (Cell Signaling Technology, \#7076; 1:3000) or anti-rabbit (Bio-Rad, Hercules, CA, USA, \#1706515; 1:3000) secondary antibodies were used.

\section{Reverse transcription and quantitative real-time PCR}

Total RNA was isolated using Trizol reagent (Invitrogen, Waltham, MA, USA) according to the manufacturer's instructions. Total RNA $(2 \mu \mathrm{g})$ was reverse transcribed using $200 \mathrm{U}$ of M-MLV reverse transcriptase (Invitrogen) in a $20-\mu \mathrm{l}$ reaction mixture at $42^{\circ} \mathrm{C}$ for $1 \mathrm{~h}$. For quantitative real-time PCR analyses, the resulting cDNA $(1 \mu \mathrm{l})$ was amplified in $10 \mu \mathrm{l}$ of Rotor-gene SYBR green (Bio-Rad). The comparative cycle-threshold $\left(\mathrm{C}_{\mathrm{T}}\right)$ method was used, and $\beta$-actin served as an endogenous control.

\section{Animal studies}

All animal experiments were performed in accordance with the guidelines of the Korean Food and Drug Administration. Protocols were reviewed and approved by the Institutional Animal Care and Use Committee of Yonsei University. The C57BL/6 J-Apc $c^{\mathrm{Min} /+}\left(\mathrm{Apc}^{\mathrm{Min} /+}\right)$ and B6.129S-Kras ${ }^{t m 3 T y j}$ mice were obtained from Jackson Laboratory (Bar Harbor, ME, USA) To generate $\mathrm{Apc}^{\mathrm{Min} / \mathrm{t}}$ / $\mathrm{Kras}^{G 12 D} \mathrm{LA} 2$ mice, $\mathrm{Apc} \mathrm{Min} / \mathrm{+}^{\mathrm{Mere}}$ crossed with $\mathrm{Kras}^{\mathrm{G12}-}$

${ }^{D} L A 2$ mice. Mouse genotyping was performed using 
genomic DNA extracted from the tail. To control for genetic background effects, sex-matched littermates were used as controls. To investigate the in vivo efficacy of KYA1 797K, 5-week-old $A p c^{\mathrm{Min} /+} / \mathrm{Kras}^{G 12 D} L A 2(N=4)$ mice were intraperitoneally injected with KYA1797K $(25 \mathrm{mg} / \mathrm{kg}) 5$ days per week for 7 weeks. Immediately after sacrifice, the abdomen of each mouse was cut open longitudinally and cleaned by flushing with PBS. The tumors were classified according to standard World Health Organization histopathological criteria. Tumor sizes were classified based on the diameter (small $\leq 1 \mathrm{~mm}, 1 \mathrm{~mm}<$ medium $\leq 3 \mathrm{~mm}$, and large $>3 \mathrm{~mm}$ ). For biochemical analyses, a subset of freshly isolated tissues was snap frozen in liquid nitrogen and stored at $-80^{\circ} \mathrm{C}$.

For the PDTX studies, athymic $n u / n u$ mice were injected subcutaneously in the dorsal flank with DLDKRAS-MT $\left(5 \times 10^{6}\right.$ cells/mice) in $200 \mu \mathrm{l}$ of PBS/Matrigel (BD Biosciences, Bedford, MA, USA; 1:1). When the mean tumor size reached between 100 and $200 \mathrm{~mm}^{3}$, the mice were randomly divided into two groups to receive either vehicle or KYA1797K. Twenty-eight days after the initial drug treatment, the mice were sacrificed, and tumors were excised and fixed in $10 \%$ neutralized formaldehyde for further analyses.

\section{Immunohistochemistry}

For IHC analyses, 4- $\mu \mathrm{m}$ paraffin-embedded tissue sections were treated with citrate buffer ( $\mathrm{pH}$ 6.0) and autoclaved for $15 \mathrm{~min}$. The sections were then blocked with $5 \%$ bovine serum albumin (BSA; Affymetrix, Santa Clara, CA, USA) and $1 \%$ normal goat serum (NGS, Vector Laboratories, Burlingame, CA, USA) in PBS for $30 \mathrm{~min}$. After blocking, sections were incubated with primary antibody overnight at $4{ }^{\circ} \mathrm{C}$ followed by incubation with anti-mouse Alexa Fluor 488- (Life Technologies, Carlsbad, CA, USA, A11008; 1:500) or anti-rabbit Alex Fluor 555-conjugated (Life Technologies, A21428; 1:500) secondary antibodies for $1 \mathrm{~h}$ at room temperature. The sections were then counterstained with 4', 6-diamidino-2phenylindole (DAPI; Sigma-Aldrich) and mounted in Gel/Mount media (Biomeda Corporation, Foster City, CA, USA). All incubations were conducted in dark, humid chambers. The fluorescence signal was visualized using a confocal microscope (LSM510; Carl Zeiss) at excitation wavelengths of $488 \mathrm{~nm}$ (Alexa Fluor 488), 543 $\mathrm{nm}$ (Alexa Fluor 555), and $405 \mathrm{~nm}$ (DAPI). At least three fields per section were analyzed.

\section{Immunocytochemistry}

The cells were fixed with $5 \%$ formalin for $30 \mathrm{~min}$, permeabilized with $0.2 \%$ Triton $\mathrm{X}-100$ for $30 \mathrm{~min}$, and preblocked with PBS containing 5\% BSA and 1\% NGS for $1 \mathrm{~h}$. The cells were then incubated with the indicated primary antibody overnight at $4{ }^{\circ} \mathrm{C}$, followed by incubation with
Alexa Fluor 488- or Alex Fluor 555-conjugated secondary antibodies for $4 \mathrm{~h}$ at $4{ }^{\circ} \mathrm{C}$. Samples were then counterstained with DAPI for $10 \mathrm{~min}$ at room temperature. After incubation, the cells were mounted in Gel/Mount media (Biomeda Corporation). The fluorescence signal was visualized using a confocal microscope (Zeiss, LSM510) at excitation wavelengths of $488 \mathrm{~nm}$ (Alexa Fluor 488), $543 \mathrm{~nm}$ (Alexa Fluor 555), and $405 \mathrm{~nm}$ (DAPI).

\section{RAS activation assay and immunoblotting}

GTP-loaded active RAS was analyzed by manufacture's procedure (Cell signaling technology, \#11860). Cells were lysed by lysis buffer plus $1 \mathrm{mM}$ PMSF, and cleared by centrifugation at $16,000 \mathrm{xg}$, for $15 \mathrm{~min}$ at $4{ }^{\circ} \mathrm{C} .500 \mu \mathrm{g}$ of cell lysates was incubated with beads coated with fusion protein (GST-Raf1-RBD) at $4{ }^{\circ} \mathrm{C}$ for $1 \mathrm{~h}$. Beads were washed 3 times with cold lysis buffer, and bounded protein was eluted with $2 x$ SDS sample buffer, incubated at $100^{\circ} \mathrm{C}$ for 5 min and analyzed by immunoblotting for RAS.

\section{Tumor organoid experiments}

For human PDC-derived tumor organoids, 250 cells per $25 \mu \mathrm{l}$ of growth factor-reduced Matrigel (BD Bioscience) were mixed, and N2 medium containing 10\% R-spondin-1 $\mathrm{CM}, 100 \mu \mathrm{g} / \mathrm{ml}$ noggin (Peprotech, Rocky Hill, NJ, USA), $1.25 \mathrm{mM} \mathrm{N}$-acetyl cysteine (Sigma-Aldrich), $10 \mathrm{mM}$ nicotinamide (Sigma-Aldrich), $50 \mathrm{ng} / \mathrm{ml}$ EGF (Peprotech), 10 $\mathrm{nM}$ gastrin (Sigma-Aldrich), $500 \mathrm{nM}$ A83-01 (Sigma-Aldrich), and $3 \mu$ M SB202190 (Sigma-Aldrich) were added. The growth medium was refreshed every 2 days, and the cells were passaged by mechanical disruption every 10-14 days at a 1:5 ratios. The measurements of tumor organoid growth were performed using the CellTiter-Glo Luminescent Cell Viability Assay (Promega, Madison, WI, USA) according to the manufacturer's instructions. Luminescence was measured with a FLUOstar Optima instrument (BMG Labtech, Ortenberg, Germany).

For mouse tumor organoid experiments, small intestinal tumors of $\mathrm{Apc}^{\mathrm{Min} / \mathrm{+}} / \mathrm{Kras}^{\mathrm{G12D}} \mathrm{LA} 2$ mice were isolated and washed with ice-cold PBS, and single cells isolated from tumors were collected using $0.25 \%$ trypsin containing $10 \mu \mathrm{M}$ Ly27632 (Sigma-Aldrich) and $100 \mu \mathrm{g} / \mathrm{ml}$ Primocin (Invivogen, San Diego, CA, USA) for $30 \mathrm{~min}$. After incubation, 1X B27 (Sigma-Aldrich) was added, and the mixture was filtered through $100-\mu \mathrm{m}$ and $40-\mu \mathrm{m}$ cell strainers (BD Biosciences) to collect single cells. The cells were then mixed with growth factor-reduced Matrigel. The growth medium was refreshed every 2 days and the cells were passaged by mechanical disruption every $10-14$ days at a $1: 5$ ratios. The measurements of tumor organoid growth were performed using the CellTiter-Glo Luminescent Cell Viability Assay according to the manufacturer's instructions, and luminescence was measured with a FLUOstar Optima instrument. 
Primary cell culture from human CRC cells and PDTX CRC PDCs that had previously been established [21] were used after receiving patient-informed consent and approval from the Institutional Review Board of Asan Medical Center. All procedures performed in studies involving human participants were conducted in accordance with the International Ethical Guidelines for Biomedical Research Involving Human Subjects. For the PDTX model, animal procedures were performed following protocols approved by the Seoul National University Institutional Animal Care and Use Committee. PDTX experiments were performed as previously described [22]. Briefly, small pieces of CRC tumors that had metastasized to lung were subcutaneously transplanted into the flanks of 5-week-old NOD/SCID mice $(N=5)$. After the tumor volumes reached $50-150 \mathrm{~mm}^{3}$, erlotinib was injected by oral gavage at a dosage of $25 \mathrm{mg} / \mathrm{kg} 5$ days per week for 28 days. KYA1797K was intraperitoneally injected into mice $(N=$ 5) at dosage of $25 \mathrm{mg} / \mathrm{kg}$ every day for 28 days. Tumor growth was determined by measurement of the short and long diameters of the tumor with a caliper, and tumor volumes were determined according to the following formula: tumor volume $\left(\mathrm{mm}^{3}\right)=($ short diameter $\mathrm{mm}) \times($ long diameter $\mathrm{mm}) \times 0.5$.

\section{Fluorescence activating cell sorting (FACS) analyses}

The sorting methods are described in our previous study [23]. Briefly, CRC cell lines (SW480, HCT116, DLD-1, SW620, SW48, and HT29) were dissociated into single cells by trypsin-EDTA, incubated with anti-human CD133-PE (Miltenyi Biotec, Bergisch Gladach, Germany), anti-human CD166-PerCP-eFluor (eBioscience, Waltham, MA, USA), and anti-human/mouse CD44-APC (eBioscience), and sorted by FACS (BD Bioscience).

\section{Statistical analysis}

All data are represented as the mean \pm standard deviation of at least three independent experiments. The statistical significance of differences was assessed using the Student's $t$-test. Significance was denoted as n.s. not significant, $" P<0.05, \stackrel{* * *}{P}<<0.01$, and ${ }^{* * * *} P<0.001$.

\section{Results}

Both Wnt/ $\beta$-catenin and RAS signaling pathways are activated in CRC harboring CSC properties

Due to the frequent mutations in the components of $\mathrm{Wnt} / \beta$-catenin and RAS pathways in CRC and their critical roles in the synergistic activation of CSCs $[15,16$, 24], we first investigated whether activation of these pathways are correlated with stem cell activities in the CRC patients. Gene set enrichment analysis (GSEA) using two differential gene expression profiles from CRC patient data sets (GSE13294; $N=125$ and GSE14333; $N=246)$ showed that genes involved in the $\mathrm{Wnt} / \beta$ - catenin and RAS pathways are simultaneously elevated in stem-like subtype of CRC patient tumors that highly express stem cell-related gene signatures (GSE13294; $N=20$ and GSE14333; $N=55$ ) [7] compared with other differentiated CRC patient tumors (Fig. 1a, b). Since simultaneous activations of Wnt/ $\beta$-catenin and RAS signaling pathways is associated with stabilizations of both $\beta$-catenin and RAS proteins by APC loss $[18,25]$, we examined the expression levels of $\beta$-catenin and RAS in the CSC-like populations which have higher spheroid forming sorted by FACS using CSC markers including CD44, CD133, and CD166 compared with those in the non-CSC populations. In addition, the CSC characteristic of CSC-like population was confirmed by their higher spheroid forming ability compared with non-CSC-population [23] (Additional file 1: Figure S1). $\beta$-catenin and RAS levels were highly elevated with activations of RAS downstream ERK and AKT kinases in CSC-like populations of CRC cell lines with various genetic backgrounds as shown by immunoblot analyses (Fig. 1c). Moreover, significant increases in the GTP-RAS, the active form of RAS, were observed in the CSC-like populations (Additional file 1: Figure S2), showing that the enriched RAS proteins in the CSC-like populations are active. These results suggest that $\beta$-catenin and RAS proteins would be effective molecular targets for suppressing the colorectal CSCs.

\section{The stem cell characteristics of CRC cell lines are suppressed by KYA1797K, the small molecule destabilizing both $\beta$-catenin and RAS}

Given that CSC-like populations of CRC cells have elevated protein levels of $\beta$-catenin and RAS, compared with non-CSC populations, we investigated whether the stem cell characteristics of CRC are associated with stabilization of $\beta$-catenin and RAS by treating the $\beta$ catenin and RAS destabilizing compound, KYA1797K [19], on the spheroid-cultured DLD-KRAS-MT CRC cells harboring both $A P C$ and KRAS mutations [16, 20]. KYA1797K effectively degraded both $\beta$-catenin, RAS, and inhibited the ERK and AKT activities (Fig. 2a) with decreased spheroid forming ability as measured by the numbers and sizes of spheroids (Fig. 2b- d). Consistent with the effects on sphere-forming ability, KYA1797K significantly reduced the mRNA levels of the CSC markers LGR5, CD44, CD133 and CD166 (Fig. 2e). Immunocytochemical analyses confirmed the KYA1797Kmediated decrease of $\beta$-catenin and RAS levels were followed by reduction of CSC markers in the DLDKRAS-MT spheroids (Fig. 2f). Flow cytometry analyses also revealed that CSC populations having $\mathrm{CD} 44^{+}$ $\mathrm{CD}_{133^{+}} \mathrm{CD} 166^{+}$triple positive cells were significantly decreased by KYA1797K (Fig. 2g; Additional file 1: Table S1). Consistently, similar inhibitory effects of KYA1797K on the CSC properties were also confirmed in SW480 


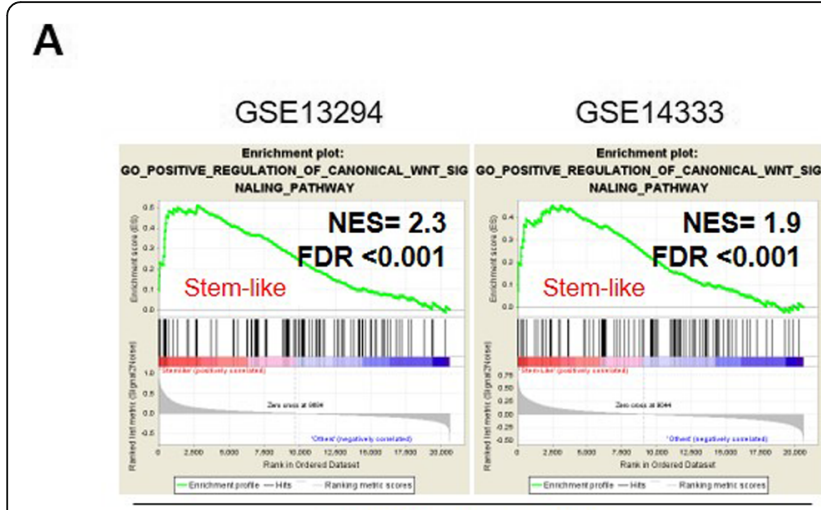

Wnt/ß-catenin pathway
B

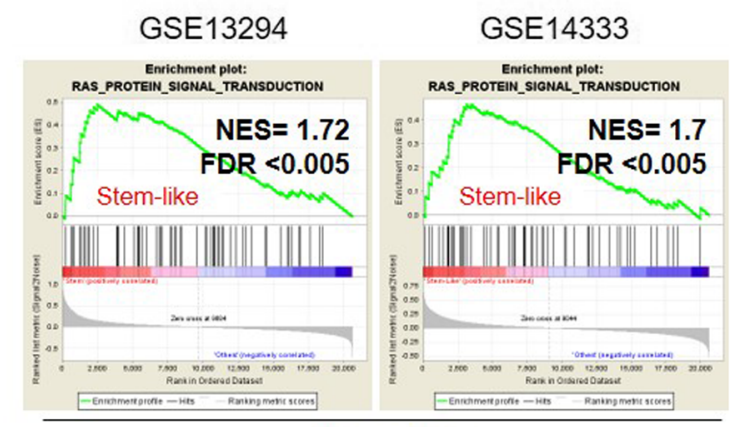

Ras pathway

C

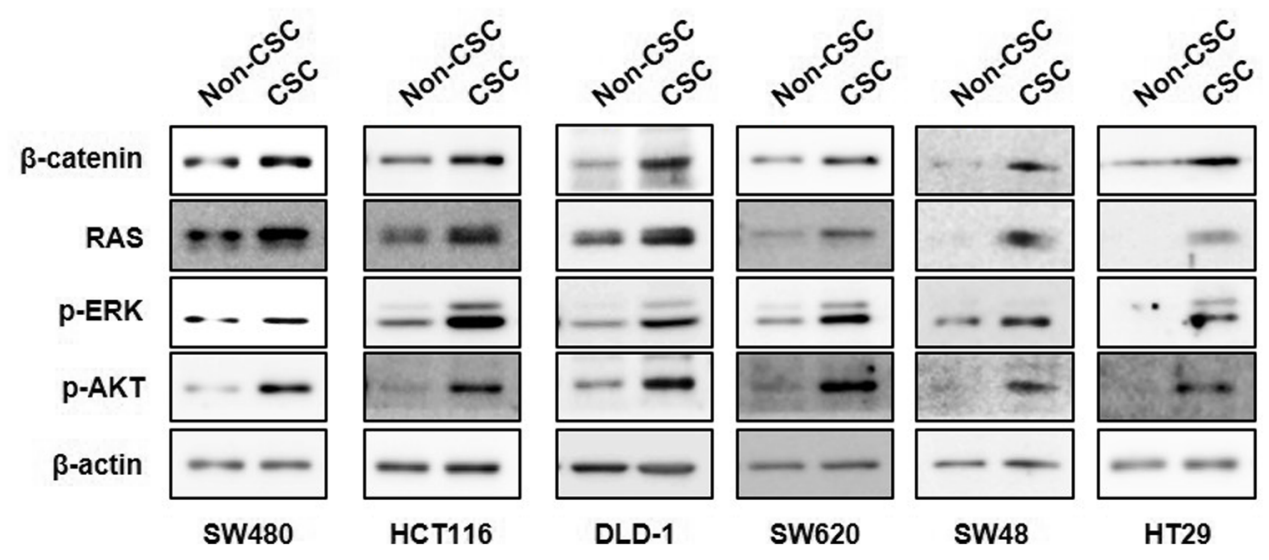

Fig. 1 Both Wnt/ $\beta$-catenin and RAS signaling pathways are activated in CRC harboring CSC properties. $\mathbf{a}$, $\mathbf{b}$ GSEA of CRC patient tissues (GSE13294, $N=125$; GSE14333, $N=246$ ) of the (a) canonical Wnt and (b) RAS pathways in the stem-like subtype of CRC tumors (GSE13294, N=20; GSE14333, N = 55) and other differentiated CRC tumors. c Immunoblot analyses of CRC cell lines comparing CSC-like (CSC) and non-CSC-like (nonCSC) populations of CRC cell lines using the indicated antibodies. CSC and non-CSC-like population of CRC cells were sorted by FACS using CD44, CD133, and CD166 antibodies

and SW620 CRC cell lines (Additional file 1: Fig. S3 AD). Moreover, immunohistochemistry (IHC) analyses of tumor tissues of DLD-1-KRAS-MT xenograft mice also revealed that KYA1797K effectively suppressed the cancer stemness of DLD-1-KRAS-MT cells (Fig. 2h).

The small molecule-induced destabilization of both $\beta$ catenin and RAS suppresses the stemness of small intestinal tumors of $A p c^{M i n /+} / K_{r a s}{ }^{G 12 D} L A 2$ mice

We examine whether KYA1797K effectively inhibit the stemness of CSCs in small intestinal tumors of $\mathrm{Apc}^{\mathrm{Min} /+}$ / Kras ${ }^{G 12 D} L A 2$ mice that exhibit synergistic activation of CSCs by $A p c$ and Kras mutations (Additional file 1: Figure S4) $[15,16]$, we tested the effects of KYA1797K on the stemness of small intestinal tumors in $\mathrm{Apc}^{\mathrm{Min} /+} / \mathrm{Kras}^{\mathrm{G12}-}$ ${ }^{D} L A 2$ mice. KYA1797K treatment decreased the levels of $\beta$-catenin and Ras proteins as well as the activities of Erk and Akt in the small intestinal tumors of the $\mathrm{Apc}^{\mathrm{Min} /+} / \mathrm{K}-$ ras $^{G 12 D} L A 2$ mice reducing both of their number and size of tumors (Fig. 3a-c). IHC analyses revealed that KYA1797K treatment significantly reduced expression levels of CD44 and CD133 (Fig. 3d) as well as the convincing intestinal CSC markers, Lrig1 and EPHB3 (Additional file 1: Figure S6). Furthermore, the growth of tumor organoids derived from small intestinal tumor cells of $A p c$ $\mathrm{Min} /+/ \mathrm{Kras}^{G 12 D} L A 2$ mice was effectively suppressed by KYA1797K treatment (Fig. 3e, f) along with significant decreases in the number and size of the tumor organoids at day 7 in the presence of EGF, R-spondin1, and Noggin, mimicking the in vivo condition of hyper-activated CSCs. (Additional file 1: Figure S5; Fig. 3g).

KYA1797K suppresses the stemness of CSC in the CRC patient tumor-derived cells (PDCs) and patient-derived tumor xenograft (PDTX)

To further explore the clinical relevance of destabilization of $\beta$-catenin and RAS in suppression of CSCs, we treated KYA1797K to CRC PDCs which detected mutation 


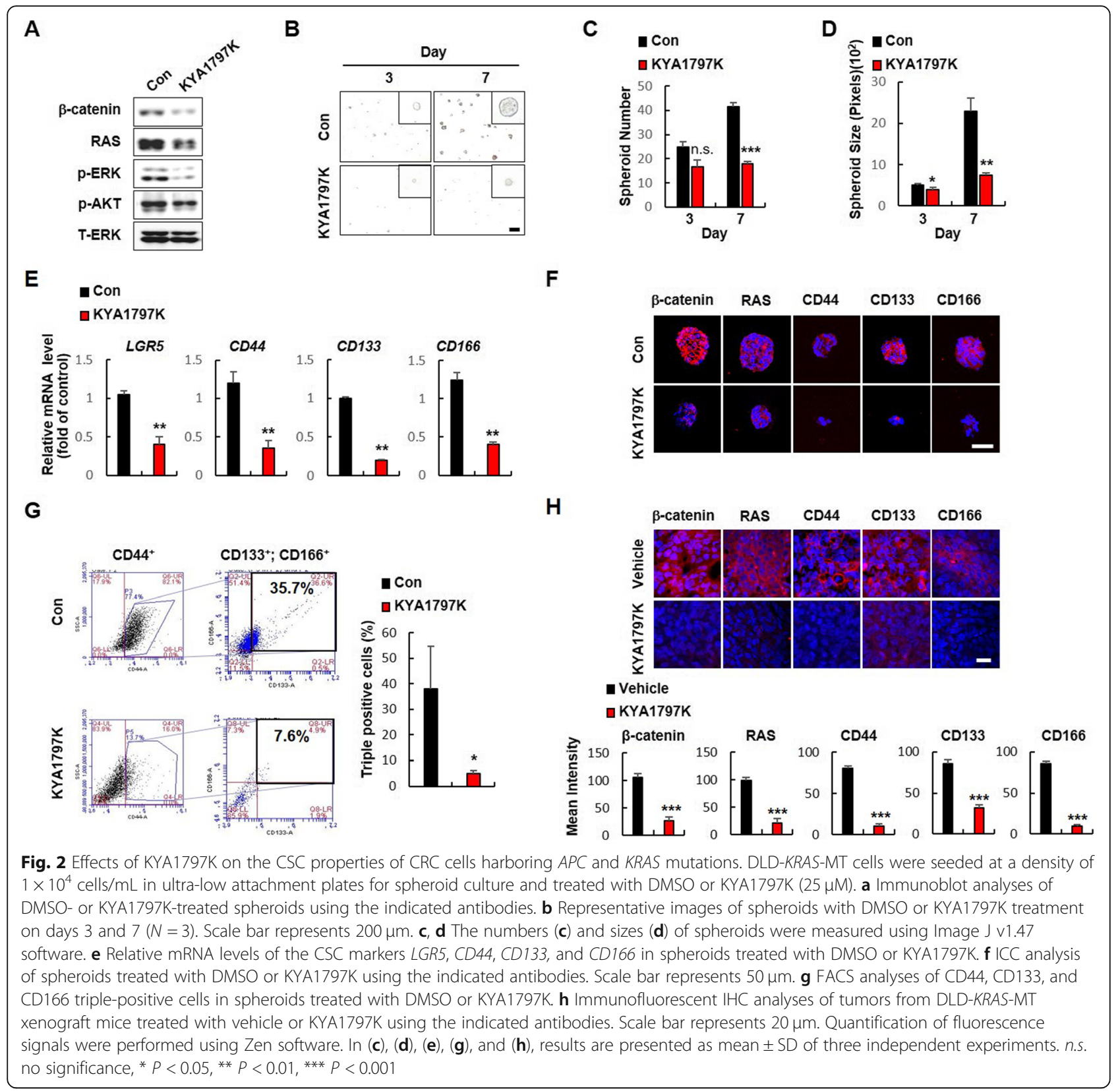

profiles of genes frequently occurred in CRC patients (Additional file 1: Table S2) [21] Treatment with KYA 1797K significantly suppressed growth of PDCs (Fig. 4a) with reduction of $\beta$-catenin and RAS levels (Fig. $4 \mathrm{~b}$ ). In addition, KYA1797K effectively reduced the expression of CSC markers in PDCs (Fig. 4c-f). The inhibitory effects of KYA1797K on the formation of tumor organoids derived from PDC1 and PDC2 further confirmed the suppression of CSC characteristics (Fig. 4g- j).

To investigate the effects of destabilization of $\beta$-catenin and RAS on CSC activation related to metastasis, we subcutaneously implanted NOD/SCID mice with KRAS mutated colon adenocarcinoma metastasized to lung, and measured effect of KYA1797K treatment. KYA1797K decreased levels of both $\beta$-catenin and RAS with inactivation of ERK and AKT kinases in the tumor lysates of the PDTX (Fig. 5a). The growth of tumors was effectively inhibited during time course up to 28 days (Fig. $5 \mathrm{~b}$ ) and tumor volumes were reduced to $58 \%$ compared to vehicle treated tumors at 28 days after KYA1797K treatment (Fig. 5c). Hematoxylin and Eosin staining analyses showed that PDTX tissues derived from colon adenocarcinoma metastasized to lung still retain the colon adenocarcinoma histology and their histology was not altered by KYA1797K treatment (Fig. 5d). Furthermore, KYA1797K effectively suppressed the expressions of CSC markers with decreased 


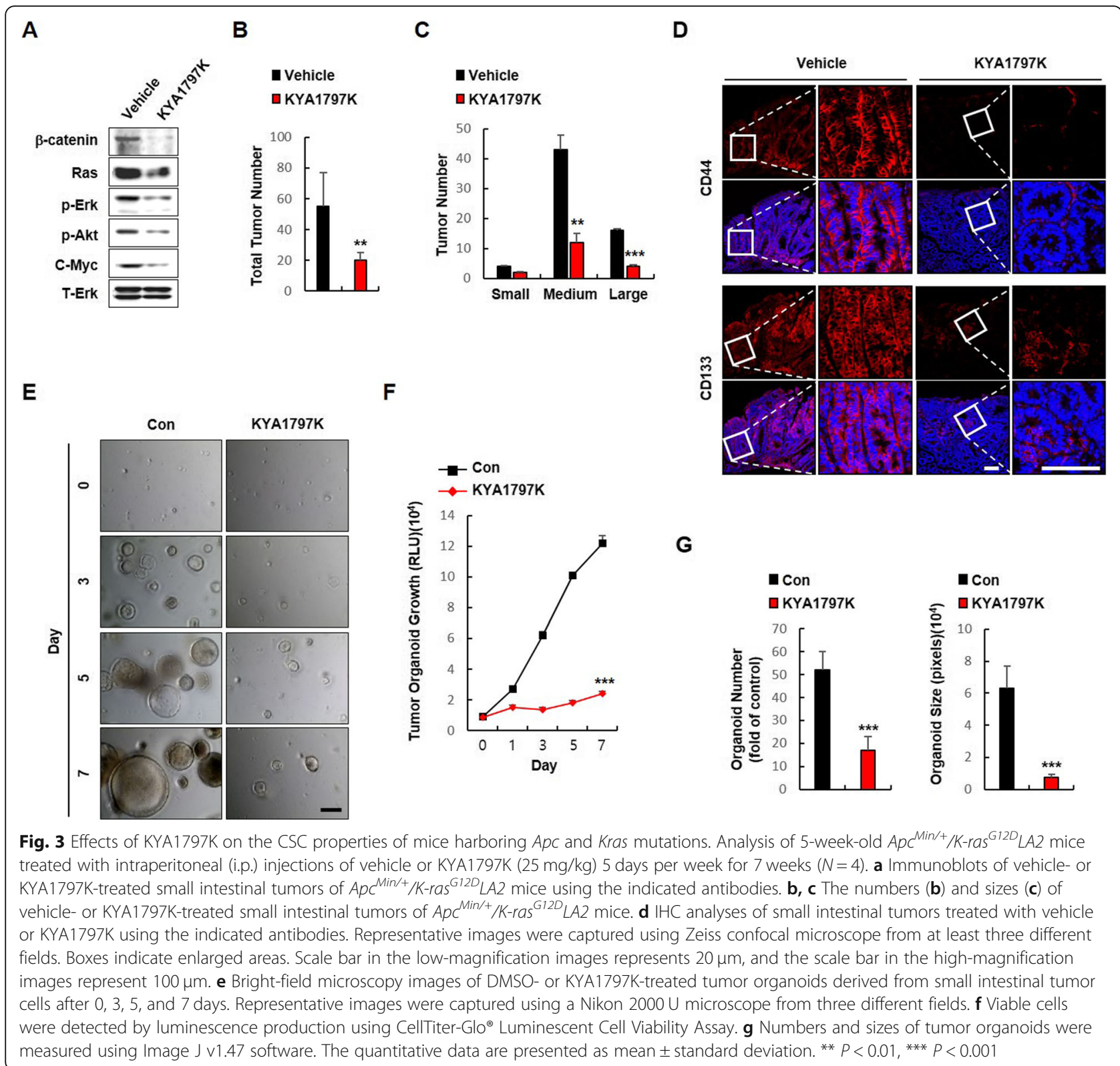

levels of $\beta$-catenin and RAS (Fig. 5e, f), while it significantly increased the expression of CK20, a convincing differentiation marker, in PDTX tissues (Additional file 1: Figure S7), suggesting that KYA1797K suppresses the stemness of CRC stem cells.

\section{Discussion}

Aberrant activation of the Wnt/ $\beta$-catenin and RAS signaling pathways with elevated $\beta$-catenin and RAS protein levels has been observed in various human cancers including CRC, gastric cancer, endometrium cancer, and non-small cell lung cancer (NSCLC) [19, 26-30]. Therefore, small molecule-mediated destabilization of both $\beta$ catenin and RAS has been shown to suppress the tumor growth in cancers such as $\mathrm{CRC}$, gastric cancer, and NSCLC The effectiveness of small molecules to many different types of cancers is due to the destabilization of $\beta$-catenin and RAS proteins which are overexpressed in the different types of cancer [19, 28-30], suggesting that stabilization of $\beta$-catenin and RAS play critical roles in regulating the activation of Wnt/ $\beta$-catenin and RAS signaling pathways in many types of cancers as well as the effect of their component gene mutation.

In CRCs, both $\beta$-catenin and RAS protein levels are highly elevated mainly due to APC mutations occurring in as many as $90 \%$ of CRC patients $[18,19,25]$. In the presence of $A P C$ mutation, additional KRAS mutation synergistically activates the $\mathrm{Wnt} / \beta$-catenin signaling via 


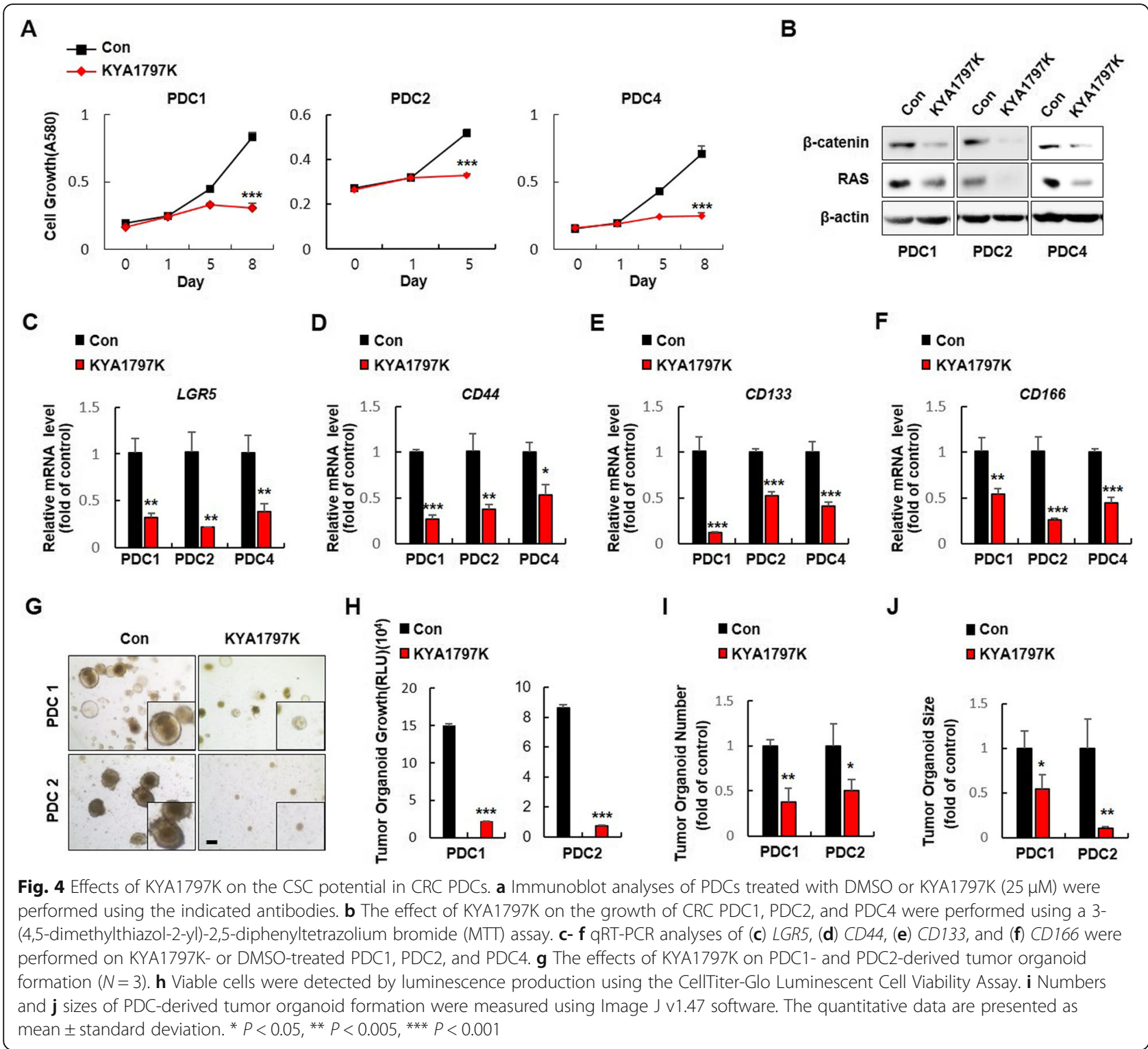

a positive feedback loop through the MEK-ERK pathway, resulting in activation of CSCs [16]. In this study, we observed that $\mathrm{Wnt} / \beta$-catenin and RAS signaling pathways are highly activated in the stem-like subtype of CRCs that possess CSC characteristics. Of interest, $\beta$-catenin and RAS protein levels as well as the active form of RAS (GTP-RAS) are significantly higher in CD44, CD133, and CD166 triple-high populations of CRC cells which possess the higher spheroid forming ability, compared with their low counterparts, suggesting that suppression of the Wnt/ $\beta$-catenin and RAS pathways, especially by reduction of the levels of $\beta$-catenin and RAS could be an effective approach to control CSCs in CRC and have led us to investigate the effects of the $\beta$-catenin and RAS destabilizing compound KYA1797K on inhibition of CRC stem cells. Destabilization of $\beta$-catenin and RAS by
KYA1797K effectively suppressed the stemness of colorectal CSCs as confirmed by suppression of the CSC markers including LGR5, CD44, CD133, and CD166 with significant inhibition of $\mathrm{Wnt} / \beta$-catenin and RAS pathways in various spheroid cultured CRC cell lines. The suppressive effects of KYA1797K on the stemness of small intestinal tumors were also confirmed in Apc$\mathrm{Min} /+^{+} / \mathrm{Kras}^{G 12 D}{ }^{\mathrm{LA} 2}$ mouse model and its small intestinal tumor cell-derived tumor organoids in the presence of EGF, Noggin, and R-spondin-1 which mimics the hyperactivation conditions of LGR $5^{+}$CSCs in vivo. Moreover, the clinical relevance of the destabilization of $\beta$-catenin and RAS by KYA1797K on the suppression of CSCs was validated by using the patient avatar models such as CRC PDCs and PDTX derived from CRC patient tissues that had metastasized to lung. Especially, considering the 


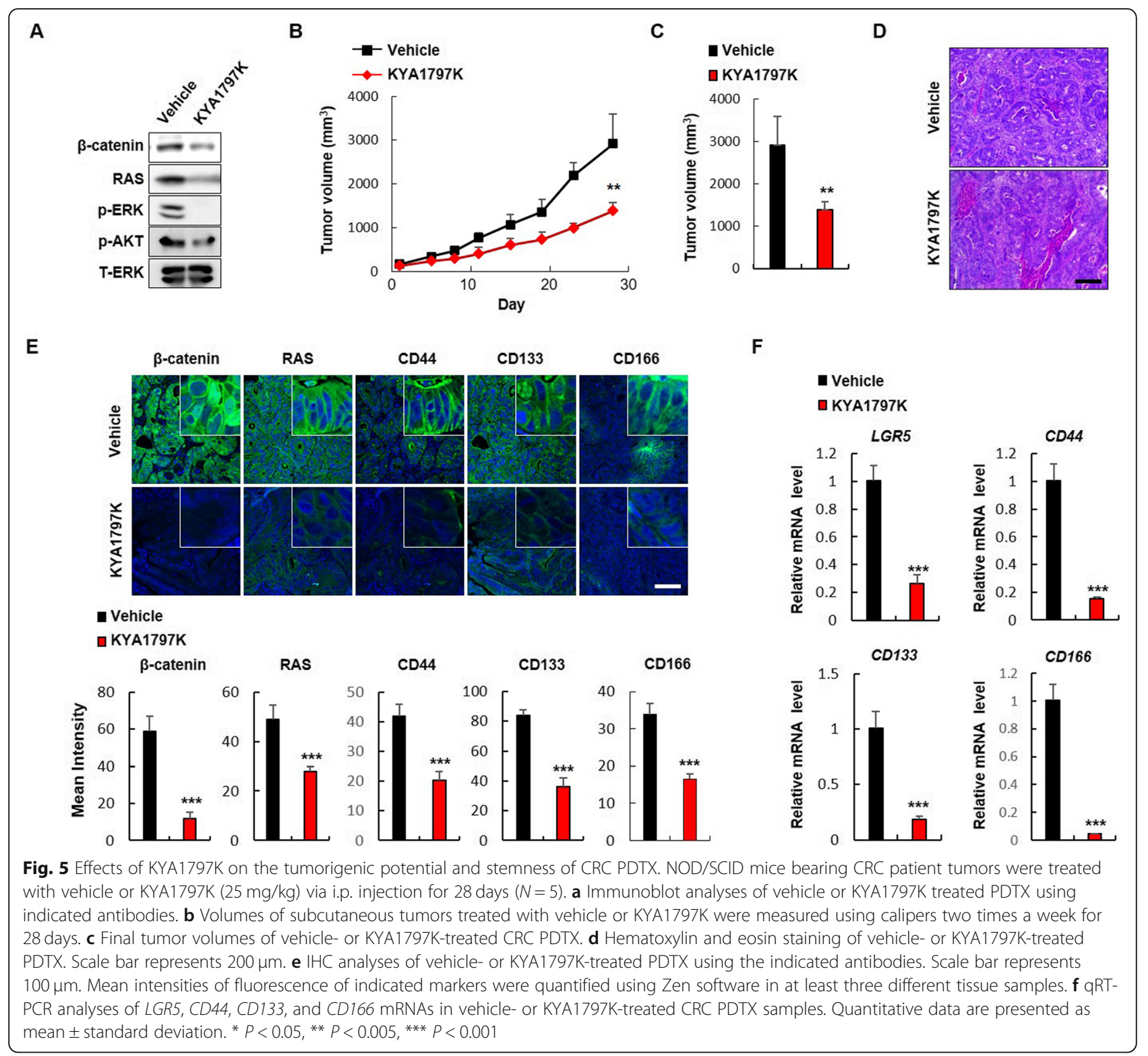

importance of CSCs in the development of metastasis [16], the inhibitory effects of KYA1797K on the growth of lung-metastasized colon cancer PDTX were confirmed with significant suppression of CSC properties and induction of differentiation, suggesting that our approach for simultaneous degradation of both $\beta$-catenin and RAS is a potential approach for suppression of metastasis as well as the stemness of CRC cells.

\section{Conclusion}

we demonstrated that small molecule-mediated destabilization of $\beta$-catenin and RAS offer a potential approach to control CSCs in CRC. Considering the importance of CSC activation in tumor metastasis and recurrence and its association with poor patient survival and drug resistance, this therapeutic approach to suppress the CSCs would be an effective strategy for improving clinical outcomes in CRC patients.

\section{Supplementary information}

Supplementary information accompanies this paper at https://doi.org/10. 1186/s12964-020-0519-z.

Additional file 1: Figure $\mathbf{S 1}$ The scheme for classifying CSC and nonCSC populations from CRC cells. Figure S2. GTP-loaded active RAS levels are highly elevated with the levels of RAS in CSC-like CRC cells compared with non-CSC cells. Figure S3. Effects of KYA1797K on CSC properties of CRC cells harboring APC and KRAS mutations. Figure S4. ApC and Kras mutations synergistically activate the CSC properties in murine small intestinal tumor cells. FACS analyses of CD44 and CD133 double-positive cells. Figure S5. LGR5 ${ }^{+}$CSCs intermingled with paneth cells which secrete EGF, R-spondin1, and Noggin were more activated than LGR5 ${ }^{+}$CSCS 
not intermingled with paneth cells. Figure S6. Effect of KYA1797K on suppression of CSC properties in small intestinal tumors of $\mathrm{ApC}^{\mathrm{Min} /+} / \mathrm{K}$ $\mathrm{ras}^{L A 2}$. Figure S7. KYA1797K significantly induces the KRT20 in CRC PDTX. Table S1. Effects of KYA1797K on CSC populations of CRC cells. Alteration of CSC marker positive cells by KYA1797K treatment were analyzed by flow cytometry. Table S2. Genetic profiles of PDC. The mutation status of APC, PIK3CA, KRAS, EGFR, PI3K, and TP53 in PDCS

\section{Abbreviations}

APC: Adenomatous polyposis coli; CRC: Colorectal cancer; CSC: Cancer stem cell; DFS: Disease free survival; ERK: Extracellular signal-regulated kinase; ISC: Intestinal stem cells; LGR5: Leucine-rich repeat-containing G-protein coupled receptor 5; PDC: Patient derived cell; PDTX: Patient derived tumor xenograft; PI3K: Phosphatidyl inositol 3-kinase

\section{Acknowledgments}

We thank B. Vogelstein (Johns Hopkins Oncology Center) for providing the Isogenic human DLD-1 CRC cell lines expressing either wild-type or mutant K-RAS (D-WT and D-MT cells, respectively).

\section{Authors' contributions}

YHC, EJR, JSY, and DKK performed the experiments. YHC, EJR, JSY, DKK, DWK and KYC performed data analysis and wrote the manuscript. All authors read and approved the final manuscript.

\section{Funding}

This work was supported by the National Research Foundation of Korea (NRF) grant funded by the Korean Government (MSIP) (grants 2016R1A5A1004694, 2019R1A2C3002751, 2018R1D1A1B07050189).

\section{Availability of data and materials}

All data in our study are available upon request.

\section{Ethics approval and consent to participate}

All animal experiments were performed in accordance with the guidelines of the Korean Food and Drug Administration. Protocols were reviewed and approved by the Institutional Animal Care and Use Committee of Yonsei University. CRC PDCs that had previously been established [21] were used after receiving patient-informed consent and approval from the Institutional Review Board of Asan Medical Center. All procedures performed in studies involving human participants were conducted in accordance with the International Ethical Guidelines for Biomedical Research Involving Human Subjects. For the PDTX model, animal procedures were performed following protocols approved by the Seoul National University Institutional Animal Care and Use Committee.

\section{Consent for publication}

Not applicable.

\section{Competing interests}

The authors declare that they have no conflicts of interests.

\section{Author details}

${ }^{1}$ Translational Research Center for Protein Function Control, Yonsei University, Seoul, South Korea. ${ }^{2}$ Department of Biotechnology, College of Life Science and Biotechnology, Yonsei University, Seoul, South Korea. ${ }^{3}$ College of Pharmacy and Research Institute of Pharmaceutical Sciences, Seoul National University, Seoul, South Korea. ${ }^{4}$ Medpacto Inc., Borim building, 92 myeongdal Ro, Seocho-gu, Seoul, South Korea. ${ }^{5}$ CK Biotechnology Inc, Building 117, 50 Yonsei Ro, Seodaemun-Gu, Seoul, South Korea.

\section{Received: 22 August 2019 Accepted: 29 January 2020}

\section{Published online: 06 March 2020}

\section{References}

1. Arnold M, Sierra MS, Laversanne M, Soerjomataram I, Jemal A, Bray F. Global patterns and trends in colorectal cancer incidence and mortality. Gut. 2017; 66:683-91.

2. Riihimaki $M$, Hemminki A, Sundquist J, Hemminki K. Patterns of metastasis in colon and rectal cancer. Sci Rep. 2016;6:29765.
3. Barker $N$, Ridgway RA, van Es $J H$, van de Wetering $M$, Begthel $H$, van den Born M, Danenberg E, Clarke AR, Sansom OJ, Clevers H. Crypt stem cells as the cells-of-origin of intestinal cancer. Nature. 2009;457:608-11.

4. Batlle E, Clevers H. Cancer stem cells revisited. Nat Med. 2017:23:1124-34.

5. de Sousa e Melo F, Kurtova AV, Harnoss JM, Kljavin N, Hoeck JD, Hung J, Anderson JE, Storm EE, Modrusan Z, Koeppen H, et al. A distinct role for Lgr5(+ ) stem cells in primary and metastatic colon cancer. Nature. 2017;543:676-80.

6. Sanchez-Danes A, Larsimont JC, Liagre M, Munoz-Couselo E, Lapouge G, Brisebarre A, Dubois C, Suppa M, Sukumaran V, Del Marmol V, et al. A slowcycling LGR5 tumour population mediates basal cell carcinoma relapse after therapy. Nature. 2018;562:434-8.

7. Sadanandam A, Lyssiotis CA, Homicsko K, Collisson EA, Gibb WJ, Wullschleger S, Ostos LC, Lannon WA, Grotzinger C, Del Rio M, et al. A colorectal cancer classification system that associates cellular phenotype and responses to therapy. Nat Med. 2013;19:619-25.

8. Fevr T, Robine S, Louvard D, Huelsken J. Wnt/beta-catenin is essential for intestinal homeostasis and maintenance of intestinal stem cells. Mol Cell Biol. 2007;27:7551-9.

9. Barker N, van Es JH, Kuipers J, Kujala P, van den Born M, Cozijnsen M, Haegebarth A, Korving J, Begthel H, Peters PJ, Clevers H. Identification of stem cells in small intestine and colon by marker gene Lgr5. Nature. 2007:449:1003-7.

10. Katoh M. Canonical and non-canonical WNT signaling in cancer stem cells and their niches: cellular heterogeneity, omics reprogramming, targeted therapy and tumor plasticity (review). Int J Oncol. 2017;51:1357-69.

11. Schmitt M, Metzger M, Gradl D, Davidson G, Orian-Rousseau V. CD44 functions in Wnt signaling by regulating LRP6 localization and activation. Cell Death Differ. 2015:22:677-89.

12. Wood LD, Parsons DW, Jones S, Lin J, Sjoblom T, Leary RJ, Shen D, Boca SM, Barber T, Ptak J, et al. The genomic landscapes of human breast and colorectal cancers. Science. 2007;318:1108-13.

13. Zenonos K, Kyprianou K. RAS signaling pathways, mutations and their role in colorectal cancer. World J Gastrointest Oncol. 2013;5:97-101.

14. Feng Y, Bommer GT, Zhao J, Green M, Sands E, Zhai Y, Brown K, Burberry A, Cho KR, Fearon ER. Mutant KRAS promotes hyperplasia and alters differentiation in the colon epithelium but does not expand the presumptive stem cell pool. Gastroenterology. 2011;141:1003-13 e1001-1010.

15. Janssen KP, Alberici P, Fsihi H, Gaspar C, Breukel C, Franken P, Rosty C, Abal M, El Marjou F, Smits R, et al. APC and oncogenic KRAS are synergistic in enhancing Wnt signaling in intestinal tumor formation and progression. Gastroenterology. 2006;131:1096-109.

16. Moon BS, Jeong WJ, Park J, Kim TI, do Min S, Choi KY. Role of oncogenic KRas in cancer stem cell activation by aberrant Wnt/beta-catenin signaling. J Natl Cancer Inst. 2014;106:djt373.

17. Guardavaccaro D, Clevers H. Wnt/beta-catenin and MAPK signaling: allies and enemies in different battlefields. Sci Signal. 2012:5:pe15.

18. Jeong WJ, Yoon J, Park JC, Lee SH, Lee SH, Kaduwal S, Kim H, Yoon JB, Choi KY. Ras stabilization through aberrant activation of Wnt/beta-catenin signaling promotes intestinal tumorigenesis. Sci Signal. 2012;5:ra30.

19. Cha PH, Cho YH, Lee SK, Lee J, Jeong WJ, Moon BS, Yun JH, Yang JS, Choi S, Yoon J, et al. Small-molecule binding of the axin RGS domain promotes beta-catenin and Ras degradation. Nat Chem Biol. 2016;12:593-600.

20. Yun J, Rago C, Cheong I, Pagliarini R, Angenendt P, Rajagopalan H, Schmidt K, Willson JK, Markowitz S, Zhou S, et al. Glucose deprivation contributes to the development of KRAS pathway mutations in tumor cells. Science. 2009;325:1555-9.

21. Kang DW, Lee BH, Suh YA, Choi YS, Jang SJ, Kim YM, Choi KY, Min DS Phospholipase D1 inhibition linked to Upregulation of ICAT blocks colorectal Cancer growth Hyperactivated by Wnt/beta-catenin and PI3K Akt signaling. Clin Cancer Res. 2017;23:7340-50.

22. Min HY, Lee SC, Woo JK, Jung HJ, Park KH, Jeong HM, Hyun SY, Cho J, Lee W, Park JE, et al. Essential role of DNA methyltransferase 1-mediated transcription of insulin-like growth factor 2 in resistance to histone Deacetylase inhibitors. Clin Cancer Res. 2017;23:1299-311.

23. Ro EJ, Cho YH, Jeong WJ, Park JC, Min DS, Choi KY. WDR76 degrades RAS and suppresses cancer stem cell activation in colorectal cancer. Cell Commun Signal. 2019;17:88.

24. D'Abaco GM, Whitehead RH, Burgess AW. Synergy between Apc min and an activated ras mutation is sufficient to induce colon carcinomas. Mol Cell Biol. 1996:16:884-91.

25. Lee SK, Jeong WJ, Cho YH, Cha PH, Yoon JS, Ro EJ, Choi S, Oh JM, Heo Y, Kim $\mathrm{H}$, et al. beta-catenin-RAS interaction serves as a molecular switch for RAS degradation via GSK3beta. EMBO Rep. 2018;19. 
26. Cho YH, Cha PH, Kaduwal S, Park JC, Lee SK, Yoon JS, Shin W, Kim H, Ro EJ, Koo KH, et al. KY1022, a small molecule destabilizing Ras via targeting the Wnt/beta-catenin pathway, inhibits development of metastatic colorectal cancer. Oncotarget. 2016;7:81727-40.

27. Koo KH, Jeong WJ, Cho YH, Park JC, do Min S, Choi KY. K-Ras stabilization by estrogen via PKCdelta is involved in endometrial tumorigenesis. Oncotarget. 2015;6:21328-40

28. Park J, Cho YH, Shin WJ, Lee SK, Lee J, Kim T, Cha PH, Yang JS, Cho J, Min DS, et al. A Ras destabilizer KYA1797K overcomes the resistance of EGFR tyrosine kinase inhibitor in KRAS-mutated non-small cell lung cancer. Sci Rep. 2019;9:648.

29. Ryu WJ, Lee JE, Cho YH, Lee G, Seo MK, Lee SK, Hwang JH, Min DS, Noh SH, Paik S, et al. A therapeutic strategy for chemotherapy-resistant gastric Cancer via destabilization of both beta-catenin and RAS. Cancers (Basel). 2019:11.

30. Lee SK, Cho YH, Cha PH, Yoon JS, Ro EJ, Jeong WJ, Park J, Kim H, II Kim T, Min DS, et al. A small molecule approach to degrade RAS with EGFR repression is a potential therapy for KRAS mutation-driven colorectal cancer resistance to cetuximab. Exp Mol Med. 2018;50:153.

\section{Publisher's Note}

Springer Nature remains neutral with regard to jurisdictional claims in published maps and institutional affiliations.

Ready to submit your research? Choose BMC and benefit from:

- fast, convenient online submission

- thorough peer review by experienced researchers in your field

- rapid publication on acceptance

- support for research data, including large and complex data types

- gold Open Access which fosters wider collaboration and increased citations

- maximum visibility for your research: over $100 \mathrm{M}$ website views per year

At BMC, research is always in progress.

Learn more biomedcentral.com/submissions 